\title{
Endofistula laser ablation of fistula-in-ano: a new minimally invasive technique for the treatment of fistula-in-ano
}

\author{
Samuel Lalhruaizela \\ Department of Surgery, Zoram Medical College, Falkawn, India
}

Purpose: Many techniques are used to treat fistula-in-ano (FIA). The major problems associated with conventional surgical techniques are postoperative complications like sepsis, incontinence, etc. Therefore, several sphincter-saving techniques have been developed in recent years including laser diodes.

Methods: This study presents an early experience of the use of diode lasers with a capacity of $360^{\circ}$ radial energy emission endofistula laser ablation (EFLA) of FIA to treat patients with primary low anal fistulas. The primary and secondary success rates were assessed and the factors affecting these rates were evaluated in patients $(n=31)$ who presented with primary, uncomplicated, and low anal fistulas.

Results: Out of 31 patients, 19 (61.3\%) were males and $12(38.7 \%)$ were females with a mean age of $38.6 \pm 11.5$ years. Twenty-one patients (67.7\%) had intersphincteric fistula, 9 (29.0\%) had transsphincteric fistula, and 1 (3.2\%) had suprasphincteric fistula. Thirteen patients (41.9\%) had undergone some surgery in the past for FIA. Eleven patients (35.5\%) developed postoperative complications. The patients had a low median pain score of 3 on the numeric pain rating scale. The primary success rate was $67.7 \%$ (21 of 31 ) and the secondary success rate was $80.0 \%$ ( 8 of 10 ) over a median followup of 2 years. A significantly higher primary healing rate was observed in patients who did not undergo any prior surgical treatments $(\mathrm{P}=0.01)$.

Conclusion: EFLA resulted in moderate primary and high secondary success rates and was not associated with major postoperative complications. Therefore, EFLA can be considered as a preferred noninvasive efficient technique for FIA treatment.

Keywords: Fistula; Sphincter; Lasers

\section{INTRODUCTION}

In recent decades, there have been many cases of anal fistula worldwide. Treatment of complex anal fistulas is difficult and is associated with the major problem of anal incontinence. For complex fistulas, fistulotomy gives good results, but patients develop

Received: Aug 5, 2020 - Revised: Dec 29, 2020 - Accepted: Apr 22, 2021 Correspondence to: Samuel Lalhruaizela, MS, FACS, DMAS

Department of Surgery, Zoram Medical College, Falkawn 796005, Mizoram, India

Tel: +91-7798296494

E-mail:samu_vuite@yahoo.co.in

ORCID: https://orcid.org/0000-0001-9991-4950

(C) 2022 The Korean Society of Coloproctology

This is an open-access article distributed under the terms of the Creative Commons Attribution NonCommercial License (https://creativecommons.org/licenses/by-nc/4.0) which permits unrestricted noncommercial use, distribution, and reproduction in any medium, provided the original work is properly cited. anal incontinence. This happens mainly in the high fistulas and in cases with a history of obstetric lesions, chronic diarrhea, and/or Crohn disease $[1,2]$. In the current scenario of clinical development, the quality of life of the patients is given the utmost importance. Therefore, recently several alternative minimally invasive sphincter-saving techniques were developed to minimize anal incontinence [3]. The techniques include ligation of the sphincteric fistula tract (LIFT), fistula clip closure techniques, advancement flap, video-assisted anal fistula treatment (VAAFT), biological glue, anal fistula plugs, over the scope clip (OVESCO), and a variety of injected materials. However, studies have shown that sustained healing with these techniques is below $50 \%[3,4]$. Therefore, an ideal anal fistula treatment should focus on sepsis removal, healing of the tract, as well as preserving the sphincters and continence.

Recently a laser-based device, 'Fistula Laser Closing' (FiLaC) 
(Biolitec AG, Jena, Germany), was used for the endofistular management. The use of laser in the treatment of anal fistula is a new concept and was only described recently in a pilot study [5]. This minimally invasive technique utilizes laser energy to carry out the process. A radial fiber emits laser beam into the fistula track causing the tissue to shrink, thus helping in the sealing process. The closure of the internal opening is achieved by an endorectal flap. Therefore, the FiLaC simultaneously destroys the epithelium of the fistula and the remaining fistula tract [5]. As the main reason for the failure of the previously used techniques is the persistence of fistula tract or leftovers of fistula epithelium, this new technique aims at eliminating the fistula tissue in a circular manner and subsequently destroys the fistula tract by shrinkage using the laser energy [6].

This study presents an early experience of the use of diode lasers with a capacity of $360^{\circ}$ radial energy emission endofistula laser ablation (EFLA) of fistula-in-ano (FIA) to treat patients with primary low anal fistulas.

\section{METHODS}

The study included 31 cases within a period of 3 years (July 2016August 2019). The study was approved by the Institutional Ethics Committee of Zoram Medical College in Falkawn, India (No. ZMC/2018/08). All the participants provided written consent for the procedure and follow-up. The study included patients (age, 15-64 years) who presented with primary, uncomplicated, and low anal fistulas. Patients with complex high anal fistulas, associated with any other syndromes including inflammatory bowel disease and/or with comorbidities including diabetes mellitus, chronic constipation, immune-compromised state, any perianal infections, and any other perianal diseases were excluded. Also, patients aged above 60 years were excluded as older patients are more likely to have comorbidities and age may affect the process of healing.

According to Park's classification, each of the cases was classified as intersphincteric fistula (IF), transsphincteric fistula (TF), suprasphincteric fistula (SF), and extrasphincteric fistulas. Magnetic resonance imaging fistulogram was used as the gold standard for diagnosis and classification. Each of the cases was assessed for the length of the fistulous tract and determined for the presence of multiple tracts. All the cases were evaluated for postoperative pain, length of hospital stay, bowel movement, and other postoperative complications, including bleeding, urinary retention, and fecal incontinence.

\section{Procedure}

The patients were treated with a radial fiber under spinal anesthesia. The external and internal orifices of the fistula track were cleaned using a curette, and then the identified orifices were irrigated using povidone-iodine and saline. A 3/0 Mitsu AB suture (triclosan coated Polyglactin-910, Meril Life Sciences, Vapi, India) was used to close the internal orifice of the internal sphincter muscle, and then the laser probe was inserted through the perineal opening. In the SFs, the laser probe was inserted first from the internal opening till it reached the turning point of the fistula track. Then the transmuscular fistula component was obliterated or closed by continuously retracting the laser fiber at a rate of 1 $\mathrm{cm}$ per 3 seconds (Fig. 1). A 3/0 Mitsu AB suture was used to close the internal opening, and then the subcutaneous part of the fistula track was treated with the laser through the outer opening. The Leonardo DUAL 45 diode laser (Biolitec AG) was used (Fig. 2) to insert the laser probe through the perineal fistula opening. Either a mucosal advancement or an anodermal flap was created to close the internal opening. No restriction in the diet was followed postoperatively. However, the patients were prescribed stool softeners for 2 weeks after surgery. Patients were evaluated at 24 hours, 7 days, and 30 days postoperatively and followed up for up to 3 years.

Permanent healing was defined as complete disappearance of all the symptoms at 1 year and no recurrence of the disease verified clinically, protoscopically, and endosonographically. Also, if there
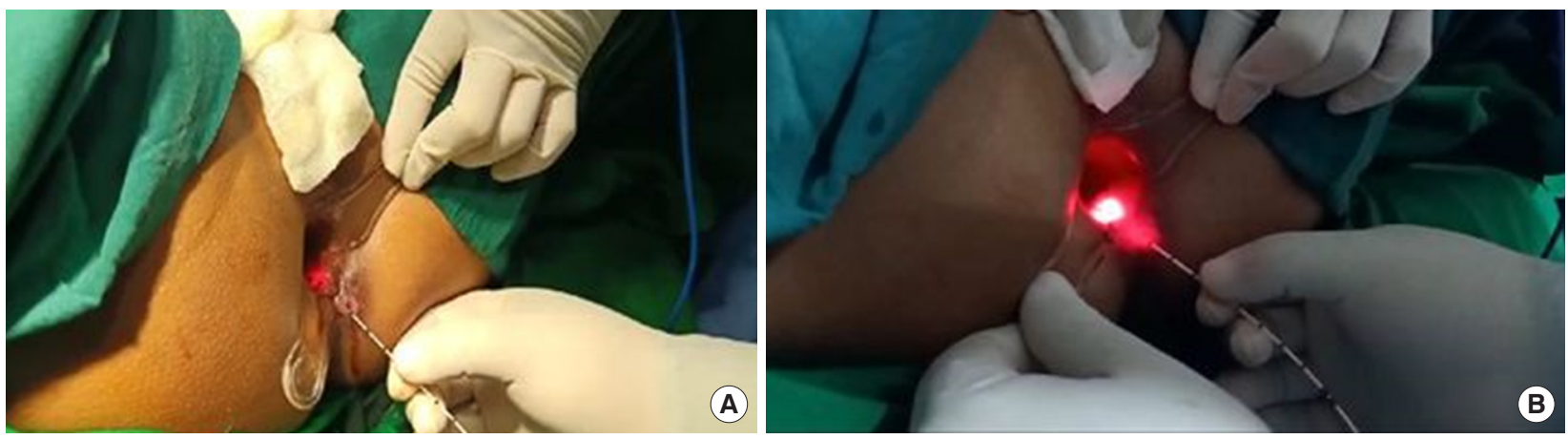

Fig. 1. (A) The $360^{\circ}$ FiLaC (Biolitec AG, Jena, Germany) laser fiber was inserted into the fistula track. The red light indicates the tip of the fiber inside the rectum. Laser was kept on stand-by and all necessary safety precautions were checked before firing. (B) The laser was activated by firing and then pulling out $1 \mathrm{~cm}$ per 3 seconds. 
Volume 38, Number 4, 2022

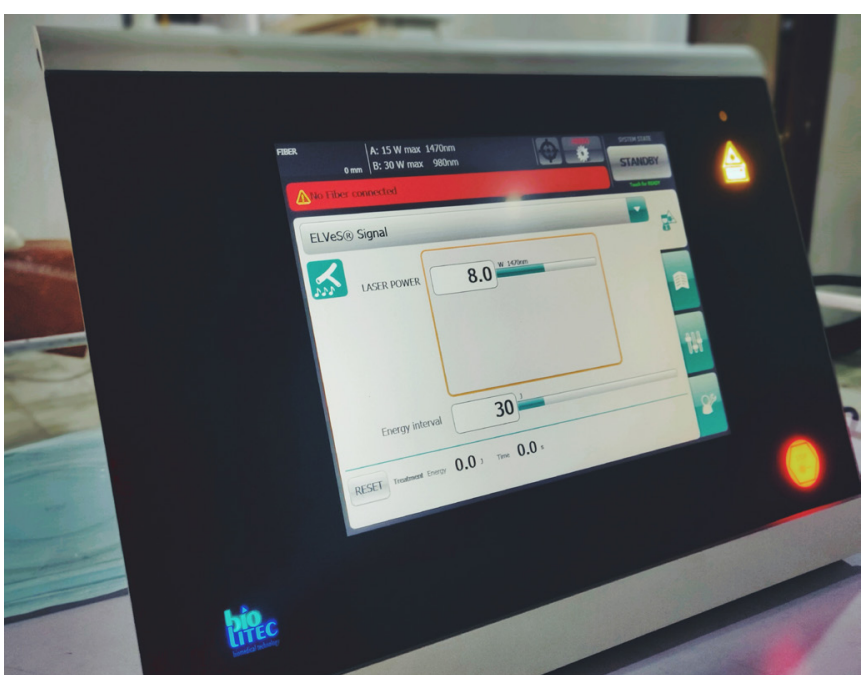

Fig. 2. Leonardo Dual 45 diode laser (Biolitec AG, Jena, Germany); dual wavelength of 980 and $1,470 \mathrm{~nm}$.

was no need for other interventions. If permanent healing was achieved after the first EFLA laser treatment, it was defined as primary healing/success and if permanent healing required a repeat surgical intervention after the first EFLA treatment failed, it was called secondary healing/success.

\section{Statistical analysis}

Statistical analysis was performed using the IBM SPSS Statistics ver. 21.0 (IBM Corp., Armonk, NY, USA). Shapiro-Wilk normality test was performed to check the distribution of the continuous variables. Categorical variables were presented as number (\%) and continuous variables as mean \pm standard deviation or median \pm interquartile range, as appropriate. Categorical variables were compared using Pearson chi-square test or Fisher exact test, as appropriate. Continuous variables were compared by Student ttest. A P-value of $<0.05$ was considered statistically significant.

\section{RESULTS}

A total of 45 patients were initially enrolled for the study out of which 31 patients fit the inclusion criteria and the rest were excluded. Table 1 explains the exclusion of a total of 14 patients from the study.

Table 2 describes the demographic and clinical details of the patients. Out of 31 patients, 19 (61.3\%) were males and 12 (38.7\%) were females. The mean age of the patients was $38.6 \pm 11.5$ years (range, 18-64 years). The mean body mass index (BMI) was $25.2 \pm 1.91 \mathrm{~kg} / \mathrm{m}^{2}$. The highest number of patients had IF $(\mathrm{n}=21$, $67.7 \%)$ followed by TF $(n=9,29.0 \%)$ and only 1 of the patients had SF $(n=1,3.2 \%)$. Eleven of the patients (35.5\%) were smokers.

Out of 31 patients, 13 (41.9\%) had undergone some form of surgery in the past for FIA. Five of them (16.1\%) had undergone fis-
Table 1. Exclusion of cases

\begin{tabular}{lc}
\hline Criteria & No. of patients $(\mathrm{n}=14)$ \\
\hline Complex high anal fistulas & 5 \\
Age more than $60 \mathrm{yr}$ & 1 \\
$\begin{array}{l}\text { Patient with other syndromes including } \\
\text { inflammatory bowel disease }\end{array}$ & 2 \\
Diabetes mellitus & 3 \\
Chronic constipation & 1 \\
Immunocompromised state & 1 \\
Perianal infections & 1 \\
\hline
\end{tabular}

Table 2. Baseline patient characteristics

\begin{tabular}{lc}
\hline Characteristic & Value $(\mathrm{n}=31)$ \\
\hline Sex & $19(61.3)$ \\
Male & $12(38.7)$ \\
Female & $38.6 \pm 11.5(18-64)$ \\
Age (yr) & $25.2 \pm 1.91$ \\
Body mass index $\left(\mathrm{kg} / \mathrm{m}^{2}\right)$ & \\
Diagnosis & $21(67.7)$ \\
Intersphincteric fistula & $9(29.0)$ \\
Transsphincteric fistula & $1(3.2)$ \\
Suprasphincteric fistula & \\
Smoking & $11(35.5)$ \\
Yes & $20(64.5)$ \\
No & $13(41.9)$ \\
Surgery in past & $5(16.1)$ \\
Fistulectomy & $3(9.7)$ \\
Ligation of Intersphincteric fistula tract & $3(9.7)$ \\
Kshar Sutra & $1(3.2)$ \\
Seton & $1(3.2)$ \\
Unknown & \\
\hline
\end{tabular}

Values are presented as number (\%) or mean \pm standard deviation (range).

tulectomy, 3 (9.7\%) had undergone LIFT, 3 (9.7\%) had undergone Kshar Sutra, 1 (3.2\%) undergone seton, and 1 (3.2\%) had undergone some unknown surgery in the past.

Numeric pain rating scale (NPRS, $0-10$ ) was used to rate the pain among patients where 0 depicts zero pain, 5 depicts moderate pain, 10 depicts the worst pain. Patients (respondents) were asked to report pain intensity 'within the last 24 hours' postoperatively. The minimum median length of stay was 1 day. The patients had a low median pain score of 3 on the NPRS. The postoperative complications are listed in Table 3.

Seven patients (22.6\%) had hemorrhage, 3 (9.7\%) had surgical site infection, and only $1(3.2 \%)$ patient showed urinary retention. Recurrence was seen in 3 patients (9.7\%). The median follow-up 
Table 3. Postoperative assessment

\begin{tabular}{lc}
\hline Parameter & Value $(\mathrm{n}=31)$ \\
\hline Pain & $3 \pm 3(2-6)$ \\
Length of stay (day) & $1 \pm 1(1-4)$ \\
Bowel movement (postoperative day) & $1 \pm 1(1-3)$ \\
Complications & \\
$\quad$ Hemorrhage & $7(22.6)$ \\
Surgical site infection & $3(9.7)$ \\
Urinary retention & $1(3.2)$ \\
Recurrence & $3(9.7)$ \\
Follow-up (yr) & $2 \pm 2(1-3)$ \\
\hline
\end{tabular}

Values are presented as median \pm interquartile range (range) or number $(\%)$.

period was 2 years.

The primary success rate was $67.7 \%$ ( 21 of 31 ) and the secondary success rate was $80.0 \%$ ( 8 of 10 ), and $20.0 \%$ ( 2 of 10 ) were intractable cases. Compared to the patients with a history of prior surgical treatments, statistically significantly higher primary success rate was observed in patients who did not undergo such prior surgical treatments $(\mathrm{P}=0.01)$. The odds of primary success rate were 12.8 times higher in patients with no history of prior surgical treatments compared to those who underwent such treatments (Table 4). There was no significant difference in the age and BMI among the patients who underwent the first EFLA laser treatment.

\section{DISCUSSION}

In the present study, we evaluated the minimally invasive EFLA as a treatment technique for the management of FIA and observed that EFLA was associated with a moderate primary success rate and high secondary success rate with very less or no postoperative complications.

The simple FIA can be easily managed by open fistulotomy with promising healing rates; however, the treatment of complex FIA remains a challenge [6]. The major challenges associated with the management of complex FIA using conventional methods are the recurrence and incontinence due to loss of sphincter function. Continuous efforts by clinicians have been in play to develop sphincter-preserving techniques to overcome the high incidence of incontinence associated with fistulotomy [7].

Several surgical procedures have been utilized to treat FIA such as LIFT, advancement flaps, and injection of biological glues like fibrin, fistula plug, VAAFT, OVESCO, and FiLaC [8-10].

In the past few decades, the laser has gained popularity in the management of many diseases. The first use of laser in the treatment of proctological disease dates back to 1981, when $\mathrm{CO}_{2}$ laser was first used to core-out cryptoglandular anal fistula tracks [11]. In 2011, FiLaC was for the first time used as a sphincter-preserv-
Table 4. Evaluation of factors affecting primary success rates after EFLA treatment

\begin{tabular}{|c|c|c|c|c|}
\hline \multirow{2}{*}{ Variable } & \multicolumn{2}{|c|}{ Primary healing } & \multirow{2}{*}{ P-value } & \multirow{2}{*}{ OR (95\% Cl) } \\
\hline & Yes & No & & \\
\hline Age $(y r)^{a}$ & $36.7 \pm 10.2$ & $42.5 \pm 13.7$ & $0.20^{\mathrm{a}}$ & \\
\hline BMI $\left(\mathrm{kg} / \mathrm{m}^{2}\right)^{\mathrm{a}}$ & $25.0 \pm 2.03$ & $25.5 \pm 1.65$ & $0.49^{\mathrm{a}}$ & \\
\hline Sex & & & 0.7 & \\
\hline Male & 12 (63.2) & $7(36.8)$ & & \\
\hline Female & $9(75.0)$ & $3(25.0)$ & & \\
\hline Diagnosis & & & 0.54 & \\
\hline IF & $13(61.9)$ & $8(38.1)$ & & \\
\hline TS & $7(77.8)$ & $2(22.2)$ & & \\
\hline SF & $1(100)$ & $0(0)$ & & \\
\hline Smoking & & & 0.42 & \\
\hline Yes & $6(54.5)$ & $5(45.5)$ & & \\
\hline No & $15(75.0)$ & $5(25.0)$ & & \\
\hline Surgery in past & & & 0.01 & \\
\hline Yes & $5(38.5)$ & $8(61.5)$ & & $0.08(0.01-0.50)$ \\
\hline No & $16(88.9)$ & $2(11.1)$ & & $12.8(2.02-81.0)$ \\
\hline
\end{tabular}

Values are presented as mean \pm standard deviation or number (\%) unless specified otherwise.

EFLA, endofistula laser ablation; OR, odds ratio; $\mathrm{Cl}$, confidence interval; BMl, body mass index; IF, in-tersphincteric fistula; TS, transsphincteric fistula; SF, suprasphincteric fistula.

aBy Student t-test.

ing procedure [5]. FiLaC uses a laser probe emitting laser energy radially producing heat that denatures the tissues in the fistula track ultimately obliterating the fistula track by shrinkage. FiLaC causes minimal damage to the sphincter complex hence the sphincter is preserved [5].

Although mixed outcomes reported, FiLaC is considered as a treatment of choice by many clinicians and investigators. The healing rates of FiLaC in treating FIA have been reported to be varying in different studies with a range of $71 \%$ to $82 \%$ over a mean follow-up period of 30 months [5, 12-14]. In a meta-analysis, the mean primary success rate was reported to be $67.3 \%$ [15].

A recent study reported the treatment outcomes of a group of 117 FIA patients by FiLaC procedure. The primary success rate was estimated over a follow-up period of more than 2 years. The reported overall primary success rate was $64.1 \%$ and the secondary success rate was $88 \%$ irrespective of the fistula type [16]. In the present study, we also observed a higher secondary success rate $(80.0 \%)$ than the primary success rate of $67.7 \%$ over a median follow-up period of 24 months, which is consistent with already published reports.

The success rate observed in the present study is comparable with the success rates of other sphincter-saving techniques such as LIFT (mean success rate of 71\%) and VAAFT (mean success 
rate of $82 \%)[8,17]$. It is highlighted in previous studies that there is no effect of patient's demographic characteristics like age, sex, etc on the primary and secondary success rates. However, the primary success rate is reported to be significantly higher in patients with intersphincteric-type fistulae [16]. In accordance with these observations, there was no effect of patient demographic characteristics such as age, BMI, gender, type of fistula, smoking habits, etc. on the primary success rates in the present study as well.

Pain and rectal tenesmus are the major postoperative complication reported associated with FiLaC treatment. Most studies have reported no major complications arising due to FiLaC [14]. In consistence with these reports, in the present study, we also did not observe any major postoperative complications. The most common postoperative complication was hemorrhage observed in $22.6 \%$ of patients. The recurrence was very low as $9.7 \%$ seen in only 3 patients in the median follow-up period of 2 years. Recurrence occurs early after FiLaC treatment due to the ligation of the epithelial tissue remnants of undetected secondary tracks before the denaturing effects of the laser come into play $[12,14]$.

The major drawback of FiLaC is the requirement of expensive accessories compared to other sphincter-preserving techniques. However, despite its high cost, the diode laser platform has advantages such as it is portable and has several other usages in surgery. For example, the laser diode can be used to treat varicose veins. Therefore, this machine can be shared for many other purposes thereby reducing the overall expenditure. Also, they are less costly than the fistula plugs [14]. Another drawback of this technique is that this technique is a blind procedure and there are chances of missing some secondary tracks [16].

The major limitation of the present study is the small sample size. Extensive prospective studies with a large sample size should be performed to further evaluate the success of EFLA in treating FIA. The present study included patients with simple low anal fistula with no other comorbidities as inflammatory bowel diseases, specifically Crohn disease. Further studies are required to evaluate the effectiveness of FiLaC in complex cases with other comorbidities.

In conclusion, despite the limitations such as the chances of missing out secondary tracks and involved costs, EFLA represents a minimally invasive first-line treatment strategy for the management of fistula. EFLA is a safe procedure associated with less postoperative complications. It shows moderate to high success rates irrespective of FIA type and most importantly preserves the sphincter complexity. However, we cannot deny the fact that these minimally invasive techniques such as EFLA can be used for selective cases and there is always a role of open surgeries or more invasive methods in case of failure of lesser invasive surgeries.

\section{CONFLICT OF INTEREST}

No potential conflict of interest relevant to this article was reported.

\section{FUNDING}

None.

\section{ACKNOWLEDGMENTS}

The author would like to acknowledge the Department of Surgery, Zoram Medical College, Mizoram, India.

\section{REFERENCES}

1. Whiteford MH, Kilkenny J 3rd, Hyman N, Buie WD, Cohen J, Orsay C, et al. Practice parameters for the treatment of perianal abscess and fistula-in-ano (revised). Dis Colon Rectum 2005;48: 1337-42.

2. Parks AG, Gordon PH, Hardcastle JD. A classification of fistulain-ano. Br J Surg 1976;63:1-12.

3. Limura E, Giordano P. Modern management of anal fistula. World J Gastroenterol 2015;21:12-20.

4. Kontovounisios C, Tekkis P, Tan E, Rasheed S, Darzi A, Wexner SD. Adoption and success rates of perineal procedures for fistulain-ano: a systematic review. Colorectal Dis 2016;18:441-58.

5. Wilhelm A. A new technique for sphincter-preserving anal fistula repair using a novel radial emitting laser probe. Tech Coloproctol 2011;15:445-9.

6. Abbas MA, Jackson CH, Haigh PI. Predictors of outcome for anal fistula surgery. Arch Surg 2011;146:1011-6.

7. Blumetti J, Abcarian A, Quinteros F, Chaudhry V, Prasad L, Abcarian H. Evolution of treatment of fistula in ano. World J Surg 2012;36:1162-7.

8. Emile SH, Elfeki H, Shalaby M, Sakr A. A Systematic review and meta-analysis of the efficacy and safety of video-assisted anal fistula treatment (VAAFT). Surg Endosc 2018;32:2084-93.

9. Narang SK, Keogh K, Alam NN, Pathak S, Daniels IR, Smart NJ. A systematic review of new treatments for cryptoglandular fistula in ano. Surgeon 2017;15:30-9.

10. Elfeki H, Hougaard HT, Duelund-Jakobsen J, Lundby L. Injection of freshly collected autologous adipose tissue for treatment of perianal fistula in a patient with Crohn's disease: a video vignette. Colorectal Dis 2019;21:981-2.

11. Slutzki S, Abramsohn R, Bogokowsky H. Carbon dioxide laser in the treatment of high anal fistula. Am J Surg 1981;141:395-6.

12. Giamundo P, Esercizio L, Geraci M, Tibaldi L, Valente M. Fistulatract Laser Closure $\left(\mathrm{FiLaC}^{\mathrm{TM}}\right)$ : long-term results and new operative strategies. Tech Coloproctol 2015;19:449-53.

13. Oztürk E, Gülcü B. Laser ablation of fistula tract: a sphincter-preserving method for treating fistula-in-ano. Dis Colon Rectum 2014;57:360-4.

14. Giamundo P, Geraci M, Tibaldi L, Valente M. Closure of fistulain-ano with laser-FiLaC ${ }^{\mathrm{TM}}$ : an effective novel sphincter-saving procedure for complex disease. Colorectal Dis 2014;16:110-5.

15. Elfeki H, Shalaby M, Emile SH, Sakr A, Mikael M, Lundby L. A 


\section{Coloproctology

systematic review and meta-analysis of the safety and efficacy of fistula laser closure. Tech Coloproctol 2020;24:265-74.

16. Wilhelm A, Fiebig A, Krawczak M. Five years of experience with the $\mathrm{FiLaC}^{\mathrm{TM}}$ laser for fistula-in-ano management: long-term follow-up from a single institution. Tech Coloproctol 2017;21:269-
76.

17. Yassin NA, Hammond TM, Lunniss PJ, Phillips RK. Ligation of the intersphincteric fistula tract in the management of anal fistula: a systematic review. Colorectal Dis 2013;15:527-35. 